\title{
UM LUGAR DE MEMÓRIA DA YOUNG MEN'S CHRISTIAN ASSOCIATION: NOS KAUTZ FAMILY YMCA ARCHIVES, OS RASTROS SOBRE A FORMAÇÃO DE DIRETORES FÍSICOS
}

\author{
Giovanna Camila Silva \\ CEMEF/EEFFTO/UFMG \\ giovannaufmg@yahoo.com.br
}

\begin{abstract}
RESUMO
O artigo apresenta os Kautz Family YMCA Archives como espaço de preservação da memória da Young Men's Christian Association e suas potencialidades para pesquisas históricas interessadas em dar visibilidade aos sujeitos, às ideias e às experiências promovidas na e pela YMCA em espaços e tempos sociais diversos. A formação de homens para trabalhar nas diferentes sedes da instituição constituiu-se como ação basilar para que os empreendimentos da Associação lograssem êxito. Destacam-se os cursos de diretores físicos promovidos pela YMCA, investigados a partir da configuração desse campo de atuação, das características desejáveis aos candidatos ao cargo e do processo de preparação em Chicago, nos Estados Unidos.
\end{abstract}

Palavras-chave: Young Men’s Christian Association. Memória. Educação Física.

\section{A PLACE OF MEMORY OF THE YOUNG MEN'S CHRISTIAN ASSOCIATION: IN THE KAUTZ FAMILY YMCA ARCHIVES, THE TRACES ABOUT THE FORMATION OF PHYSICAL DIRECTORS}

\begin{abstract}
The article presents the Kautz Family YMCA Archives as a preservation space of the memory of the Young Men's Christian Association and its potential for historical research aimed at giving visibility to the experiences, ideas and individuals, promoted in and by the YMCA in different spaces and social times. The formation of men to work in the different headquarters of the institution was constituted as basic action for the success of the Association. Of particular note are the courses of physical directors promoted by the YMCA, investigated from the perspective of this field, the candidates desirable characteristics for the position and the preparation process in Chicago, United States.
\end{abstract}

Keywords: Young Men’s Christian Association. Memory. Physical Education.

UN LUGAR DE MEMORIA DE LA YOUNG MEN'S CHRISTIAN ASSOCIATION: EN LOS KAUTZ FAMILY YMCA ARCHIVES, LOS RASTROS SOBRE LA FORMACIÓN DE DIRECTORES FÍSICOS

\section{RESUMEN}

El artículo presenta los Kautz Family YMCA Archives como espacio de preservación de la memória de la Young Men's Christian Association y sus potencialidades para investigaciones históricas interesadas en dar visibilidad a los sujetos, a las ideas y a las experiéncias promovidas en la y por la YMCA en espacios y tiempos sociales diversos. La formación de hombres para trabajar en las diferentes cedes de la institución se constituye como una acción fundamental 
para que los emprendimentos de la asociación tengan éxito. Se destacan los cursos de directores físicos promovidos por la YMCA, investigados a partir de la configuración de ese campo de actuación, de las características deseables a los candidatos al cargo y del proceso de preparación en Chicago, Estados Unidos.

Palabras clave: Young Men's Christian Association. Memoria. Educación Física.

\section{UN LIEU DE MÉMOIRE DE L' YOUNG MEN'S CHRISTIAN ASSOCIATION: DANS LES KAUTZ FAMILY YMCA ARCHIVES, LES TRACES SUR LA FORMATION DES DIRECTEURS PHYSIQUES}

\section{RÉSUMÉ}

Cet article présente les Kautz Family YMCA Archives comme un espace de préservation de la mémoire de l'Young Men's Christian Association et son potentiel pour la recherche historique visant à donner de la visibilité aux sujets, idées et expériences promus dans et par l'YMCA en différents espaces et temps sociaux divers. La formation des hommes pour travailler dans les différents sièges de l'institution a constitué une action de base pour le succès des entreprises de l'Association. Il convient de noter en particulier les cours de directeurs physiques promus par l'YMCA, ici étudiés à partir de la configuration de ce champ d'action, des caractéristiques souhaitables aux candidats à ce poste et de leur processus de préparation à Chicago, aux ÉtatsUnis.

Mots-clés: Young Men's Christian Association. Mémoire. Éducation Physique.

\section{INTRODUÇÃO}

Originada na Inglaterra e com marcada presença nos Estados Unidos, a Young Men's Christian Association (YMCA) expandiu-se por diferentes lugares ao redor do mundo. Um mesmo lugar institucional que recebeu denominações distintas em função de sua localidade: Asociación Cristiana de Jóvenes (ACJ) em países de língua espanhola (exceção faz-se ao México, onde a denominação também é YMCA, embora com pronúncia diferente), e Associação Cristã de Moços (ACM) em países de língua portuguesa.

Adotando minha experiência de investigação nos Kautz Family YMCA Archives como ponto de partida, este artigo pretende apresentar elementos promissores para pesquisas interessadas na história da Young Men's Christian Association e sua presença em diferentes países da América, seus projetos educativos, especialmente, aqueles relativos à constituição de uma modelagem para a Educação Física. Para este texto, destaca-se a formação de diretores físicos em Chicago, que atuaram em sedes da Associação no Brasil. São eles: Henry James Sims, Frederico Guilherme Gaelzer e Renato Eloy de Andrade. Eles transitaram por diferentes países, inscreveram-se em relações institucionais, tiveram competências a eles atribuídas e assim articularam ideias, práticas e culturas. Compreendidos como mediadores culturais, "como 
agentes de mobilização, torna-se fundamental seguir suas pistas, atentar para suas experiências, nos tempos e lugares diversos onde e quando estiveram e atuaram, que contatos estabeleceram, de que dinâmicas coletivas participaram" (FONSECA, 2013, p. 69). Ao assumir a argumentação de Faria Filho, Chamon e Inácio, de que "mais do que o que esses sujeitos pensaram, o que se quer pôr em cena é como esses sujeitos puderam pensar o que pensaram" (2009, p. 7), tornou-se imperativo perseguir rastros que pudessem revelar suas trajetórias no interior da instituição com a qual mantiveram vínculos, a Associação Cristã de Moços.

Integrante da biblioteca da Universidade de Minnesota, em Minneapolis, os Kautz Family YMCA Archives organizam, preservam e fornecem acesso à documentação da YMCA nos Estados Unidos e nos demais países em que a instituição constituiu sedes. A preservação documental relativa ao acervo da YMCA teve início em 1877 como uma coleção particular de Jacob Bowne, um acemista, que organizou um conjunto de materiais para servir à formação de novos membros daquela instituição. A documentação reunida transformou-se em uma biblioteca corporativa, para em seguida constituir-se como um arquivo universitário que atende pesquisadores de todo o mundo. Na década de 1990, um empressário chamado Richard C. Kautz, que também mantinha vínculo com a Associação, e sua família realizaram uma doação com o intuito de financiar um projeto de preservação dos registros da YMCA. Por isso, os arquivos receberam a denominação "Kautz"1.

No processo de guarda dos documentos, possivelmente diferentes foram as intencionalidades presentes na tomada de decisão acerca daquilo que seria preservado, cuidado e disponibilizado. Os sentidos e significados históricos presentes nos livros, nos periódicos, nas correspondências, nos mapas e nas demais produções institucionais, dão a ver o que se pretendeu deixar ser revelado. Como afirma Le Goff (1997, p.101):

\footnotetext{
Os documentos não aparecem, aqui ou ali, pelo efeito de um qualquer imperscrutável desígnio dos deuses. A sua presença ou a sua ausência nos fundos dos arquivos, numa biblioteca, num terreno, dependem de causas humanas que não escapam de forma alguma à análise, e os problemas postos pela sua transmissão, longe de serem apenas exercícios de técnicos, tocam, eles próprios, no mais íntimo da vida do passado, pois o que assim se encontra posto em jogo é nada menos do que a passagem da recordação através das gerações.
}

Nesse arquivo institucional, memórias relativas às diferentes frentes de trabalho da YMCA, inclusive aquelas relacionadas à Educação Física e aos esportes. Seu conjunto documental é formado por registros de arquivo que incluem atas de reuniões, correspondências

\footnotetext{
${ }^{1}$ Disponível em <https://www.lib.umn.edu/ymca/archives-history-mission>. Acesso em: 01 maio 2018.
} 
e memorandos, pesquisas e relatórios, recortes de notícias, registros financeiros e de pessoal, panfletos, mapas, gráficos, esquemas; por fotografias, postais e álbuns de recortes; por vídeos e gravações de áudio; por pôsteres e panfletos que informam sobre eventos, programas e campanhas de divulgação da Associação; por objetos tridimensionais; por livros, reunidos em mais de 5.000 exemplares; e por periódicos ${ }^{2}$.

Nos Kautz Family YMCA Archives, três coleções me interessaram de forma mais contundente para constituição de fontes: YMCA International Work in Brazil: An Inventory of Its Records; George Williams College: An Inventory of Its Records e YMCA Biographical Files: An Inventory. A primeira é composta por correspondências, relatórios e material impresso sobre o trabalho internacional da YMCA no Brasil, principalmente no Rio de Janeiro e São Paulo ${ }^{3}$. A segunda possui registros que documentam operações, administração e produção acadêmica do George Williams College $e^{4}$ desde as suas origens na década de 1880. A terceira constitui-se de material biográfico de líderes da YMCA nos Estados Unidos. A quantidade e os tipos documentais são variados para cada um dos sujeitos que constam na listagem da coleção. Para alguns deles, existem apenas registros biográficos básicos. Para outros, um conjunto substancial de documentos que abrange diários, manuscritos, recortes, correspondências, relatórios, entre outros $^{5}$. No conjunto de fontes, foram encontrados indícios: da constituição da YMCA; dos itinerários de diferentes sujeitos que fizeram da YMCA seu lugar de formação e/ou atuação; do investimento na construção das sedes acemistas no Brasil; do processo de especialização em Educação Física, que resultou no estabelecimento de uma nova profissão dentro da Associação: o diretor físico.

Esse valioso acervo, indagado a partir de múltiplas questões, permite a escrita de diferentes histórias. A que se narra a seguir coloca em cena o instituto de formação da YMCA em Chicago e a preparação de diretores físicos ali empreendida.

\footnotetext{
${ }^{2}$ Disponível em <https://www.lib.umn.edu/ymca/collection-information>. Acesso em: 01 maio 2018.

${ }^{3}$ Disponível em <http://special.lib.umn.edu/findaid/html/ymca/yusa0009x2x12.phtml\#a5>. Acesso em: 02 abr. 2016.

${ }^{4}$ No George Williams College estudaram os sujeitos nesse estudo investigados. Sims estudou na instituição ainda quando denominada Institute and Training School of the YMCA (ITS), e Gaelzer e Andrade quando conhecida como YMCA College or Association College.

${ }^{5}$ Disponível em <http://special.lib.umn.edu/findaid/html/ymca/yusa0012.phtml>. Acesso em: 02 abr. 2016.
} 


\section{A YOUNG MEN'S CHRISTIAN ASSOCIATION - YMCA E A FORMAÇÃO DE DIRETORES FÍSICOS: A PREPARAÇÃO ESPECIALIZADA EM CHICAGO}

Nomeado como Western Secretarial Institute em 1884, redesignado como The Young Men's Christian Association Training School em 1890, e denominado como Young Men's Christian Association College a partir de 1913, o Instituto de preparação técnica da YMCA em Chicago foi resultado do anseio de líderes da Associação do meio oeste dos Estados Unidos que demandavam o treinamento profissional de seu quadro funcional. O propósito do Instituto consistia no treinamento, educação e ajuste de secretários e diretores físicos da YMCA “instruindo-os na palavra de Deus e na prática da Associação Cristã de Moços"6.

A formação de secretariado para trabalhar nas diferentes sedes da YMCA constituiuse como ação basilar para que os empreendimentos da Associação lograssem êxito. Com o andamento das ações da instituição, uma nova especialidade de formação começou a ser gestada no seu interior, aquela voltada para a preparação de diretores físicos. O ofício ali constituído dava visibilidade à crescente importância que as intervenções sobre o corpo dos associados ganhavam na instituição.

Muitos foram os diretores físicos formados pela YMCA que assumiram o trabalho internacional realizado pela instituição. "Dos Estados Unidos, os seus directores de educação physica têm sido chamados literalmente aos fins do mundo, onde sua missão como apostolos de saude tem sido coroadas (sic) de grande exito. São universalmente recebidos e bem vindos", anunciava a Mocidade, impresso oficial das Associações Cristãs de Moços no Brasil ${ }^{7}$. Para a sede acemista no Rio de Janeiro, Henry James Sims, estadunidense que estudou na escola de treinamento em Chicago, foi quem ocupou a direção do departamento físico no ano de 1913.

Foi também no Instituto e Escola de Treinamento da Associação Cristã de Moços, em Chicago, que estudaram Frederico Guilherme Gaelzer e Renato Eloy de Andrade. O primeiro foi Diretor de Jardins de Recreio em Porto Alegre desde meados da década de 1920 e Inspetor de Educação Física no Rio Grande do Sul a partir da década de 1930; o segundo, ocupou o cargo central da Inspetoria de Educação Física de Minas Gerais, no período de 1928 a 1937.

Como lugar de preparação, de fermentação de ideias, de conexão de sujeitos, a instituição em Chicago compôs os itinerários formativos dos diretores físicos destacados nesse

\footnotetext{
6 The Young Men's Christian Association College. Announcements for 1920-21. April, 1920, p. 18 . Box 114. George Williams College: an inventory of its records. Kautz Family YMCA Archives. University of Minnesota (tradução livre).

${ }^{7}$ Mocidade, junho de 1921, n. 328, p. 7.
} 
estudo $^{8}$. Desse processo, que comportou saberes compartilhados e apropriações singulares, buscou-se apreender os arranjos e os procedimentos para uma formação especializada em modos de educar o corpo.

A configuração da preparação técnica na instituição sofreu modificações, por vezes sutis, ao longo de sua história. Mudanças de denominação, alterações de espaço e de estrutura, transformações no plano de estudos, dentre outras, constituem diferenças nas formações de Sims, Gaelzer e Andrade. Considerando seus tempos de formação, a narrativa que organiza este trabalho foi estabelecida em dois momentos. Primeiramente, são apresentados aspectos da formação de Sims, porque teria iniciado seus estudos no período de 1907-1908 . Em seguida, a composição dos estudos de Gaelzer e Andrade, porque partilharam um período de estudos semelhante. Respectivamente, os períodos de 1919-1920 e 1920-1921 constam como seu primeiro ano de formação na instituição. Um movimento de idas e vindas a alguns temas, ações e estratégias, que aparecem como elementos da formação dos diretores físicos.

\section{A FORMAÇÃO DE SIMS}

No catálogo anual do The Institute and Training School Young Men's Christian Associations referente ao período de 1908 a 1909, Henry Sims consta como estudante júnior. Nesse momento, o Instituto parecia não ter construção própria e utilizava a estrutura da Associação em Chicago: escritórios, biblioteca, salas de aula, um ginásio, uma quadra de handebol, natatório e banheiros, laboratório de histologia e química. Para as aulas de anatomia em laboratório, as acomodações utilizadas pertenciam à Northwestern University Dental School. Além dos equipamentos em Chicago, o Instituto ainda mobilizava espaços em Lake Geneva. Ali, os estudantes passavam o chamado summer term, momento integrante da formação e, no tocante aos espaços para o trabalho físico, sua estrutura contava com um ginásio, campo para jogos, quadras de tênis, espaço para golfe, um píer para natação, barcos a remo, canoas e iates à vela. $\mathrm{O}$ curso regular para os alunos aspirantes a diretores físicos consistia em nove períodos de estudo em Chicago, e dois em Lake Geneva, totalizando três anos de preparação.

Dos critérios elencados para admissão no curso, Sims em uma autobiografia relata o atendimento a vários deles: já era maior de 18 anos, teve sucesso como empregado na

\footnotetext{
${ }^{8}$ Sobre a noção de itinerários e construção de trajetórias intelectuais, cf. Sirinelli (2003), Alves (2012).

${ }^{9} \mathrm{O}$ calendário letivo na escola de formação em Chicago compreendia dois anos cronológicos subsequentes. Em geral, o período escolar tinha início no segundo semestre e terminava no primeiro semestre do ano seguinte.
}

Rev. Iberoam. Patrim. Histórico-Educativo, Campinas (SP), v. 4, n. 1, p. 38-51, jan./jun. 2018 
Associação, tinha habilidade com ginástica, esportes e jogos ${ }^{10}$. Esta última, requisito específico para aspirantes a diretores físicos. Além destes, o Instituto exigia que o candidato fosse membro de alguma igreja evangélica, tivesse concluído um bom curso de estudos referentes ao high school e, particularmente para o curso frequentado por Sims, conhecimento elementar em física e química. Condições que reforçam o sentido religioso do trabalho na Associação, a ideia de vocação para dar cumprimento ao projeto acemista, a valorização da experiência prática e a necessidade de um repertório de saberes teóricos ${ }^{11}$.

Organizada em cinco departamentos de instrução - estudos bíblicos e sociais; história, filosofia e administração da Associação; promoção e publicidade da Associação; treinamento físico, e visitação e prática - a Escola proporcionava uma formação baseada em diferentes saberes. A tabela abaixo apresenta a distribuição das matérias sob responsabilidade de cada um dos departamentos da instituição durante os três anos da preparação de diretores físicos, bem como, o momento em que os alunos teriam a instrução em cada uma delas.

Tabela 1: o agrupamento e a sequência de estudos para diretores físicos em 1908.

\begin{tabular}{|c|c|c|c|c|c|c|c|c|c|c|c|c|}
\hline \multirow{3}{*}{ MATÉRIAS } & \multicolumn{4}{|c|}{ Primeiro ano } & \multicolumn{4}{|c|}{ Segundo ano } & \multicolumn{4}{|c|}{ Terceiro ano } \\
\hline & 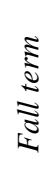 & 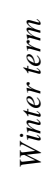 & 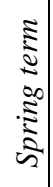 & 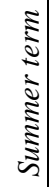 & $\begin{array}{l}\mathbf{\Xi} \\
\vdots \\
\Xi \\
\bar{\Xi} \\
\leq\end{array}$ & 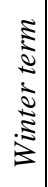 & 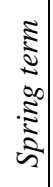 & 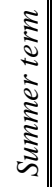 & 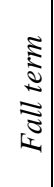 & 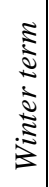 & $\begin{array}{c}\Sigma \\
\mathbf{5} \\
2 \\
00 \\
.5 \\
5 \\
5\end{array}$ & $\begin{array}{l}\vdots \\
\vdots \\
\vdots \\
\text { ఏ } \\
\text { ज }\end{array}$ \\
\hline & \multicolumn{12}{|c|}{ Aulas por semana } \\
\hline I. ESTUDOS BÍBLICOS E SOCIAIS & & & & & & & & & & & & \\
\hline A vida de Cristo ............... & 4 &.. &.. &.. &.. &.. &. &. &.. &.. &. & $\cdot \cdot$ \\
\hline 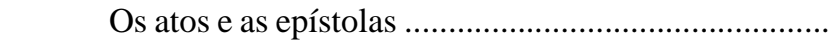 & .. & 4 & .. & .. & .. & .. & .. & .. &.. & .. & .. & .. \\
\hline Os ensinamentos de Jesus e seus apóstolos ............... & .. & .. & 3 & .. & .. & .. & .. & .. & .. & .. & .. & .. \\
\hline 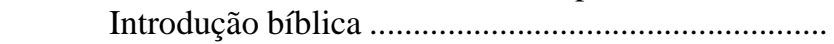 & .. & .. & .. & 5 & .. & .. & .. & .. & .. & .. & .. & .. \\
\hline 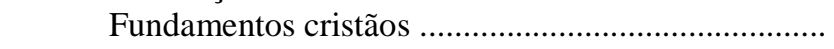 & .. & .. & .. & .. & .. & .. & .. & .. & .. & .. & 2 & .. \\
\hline História do velho testamento e profecia .................... &.. & .. & .. & .. & 2 & 2 & 2 & .. & .. & .. & .. & .. \\
\hline Início da história Hebraica ................................... & .. & .. & .. & .. & .. & .. & .. & .. & 3 & .. & .. &.. \\
\hline 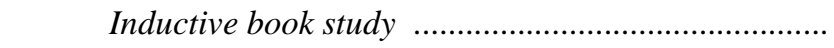 & .. & .. & .. & .. & .. & .. & .. & 5 & .. & .. & .. & .. \\
\hline 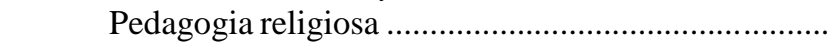 & .. & .. & .. & .. & .. & .. & 2 & .. & .. & .. & .. & .. \\
\hline 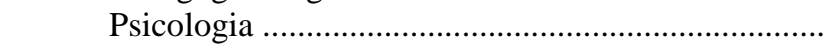 & .. & .. & .. & .. & .. & .. & .. & .. & 4 & 4 & .. & .. \\
\hline Sociologia ......................... &.. & .. & .. & .. &. &.. & .. & .. &.. & 4 & 3 &.. \\
\hline 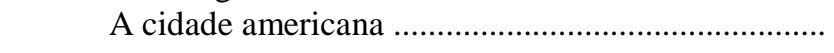 &.. & .. & .. &.. & .. & .. & .. &.. &.. & .. & 2 &.. \\
\hline $\begin{array}{l}\text { II. HISTÓRIA, FILOSOFIA E ADMINISTRAÇÃO DA } \\
\text { ASSOCIAÇÃO }\end{array}$ & & & & & & & & & & & & \\
\hline História e administração . & 2 &.. &.. &.. & .. &.. &.. &.. &.. & .. &.. &.. \\
\hline Seminário .................. & 1 & .. & 1 & .. & 1 & .. & 1 & .. & 1 &.. & 1 &.. \\
\hline 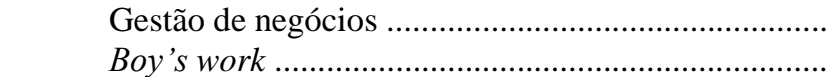 & .. & 1 & $\ddot{2}$ & .. & $\begin{array}{l}. . \\
. .\end{array}$ & $\begin{array}{l}. . \\
. .\end{array}$ & .. & .. & .. & .. & .. & .. \\
\hline
\end{tabular}

\footnotetext{
${ }^{10}$ Henry James Sims biography, s/d, s/p. Box 187. YMCA Biographical Files: an inventory. Kautz Family YMCA Archives. University of Minnesota (tradução livre). Documento manuscrito, com texto em primeira pessoa.

${ }^{11}$ The Institute and Training School of Young Men's Christian Associations. Catalog and annual announcement. May, 1908. Box 114. George Williams College: an inventory of its records. Kautz Family YMCA Archives. University of Minnesota (tradução livre).
} 


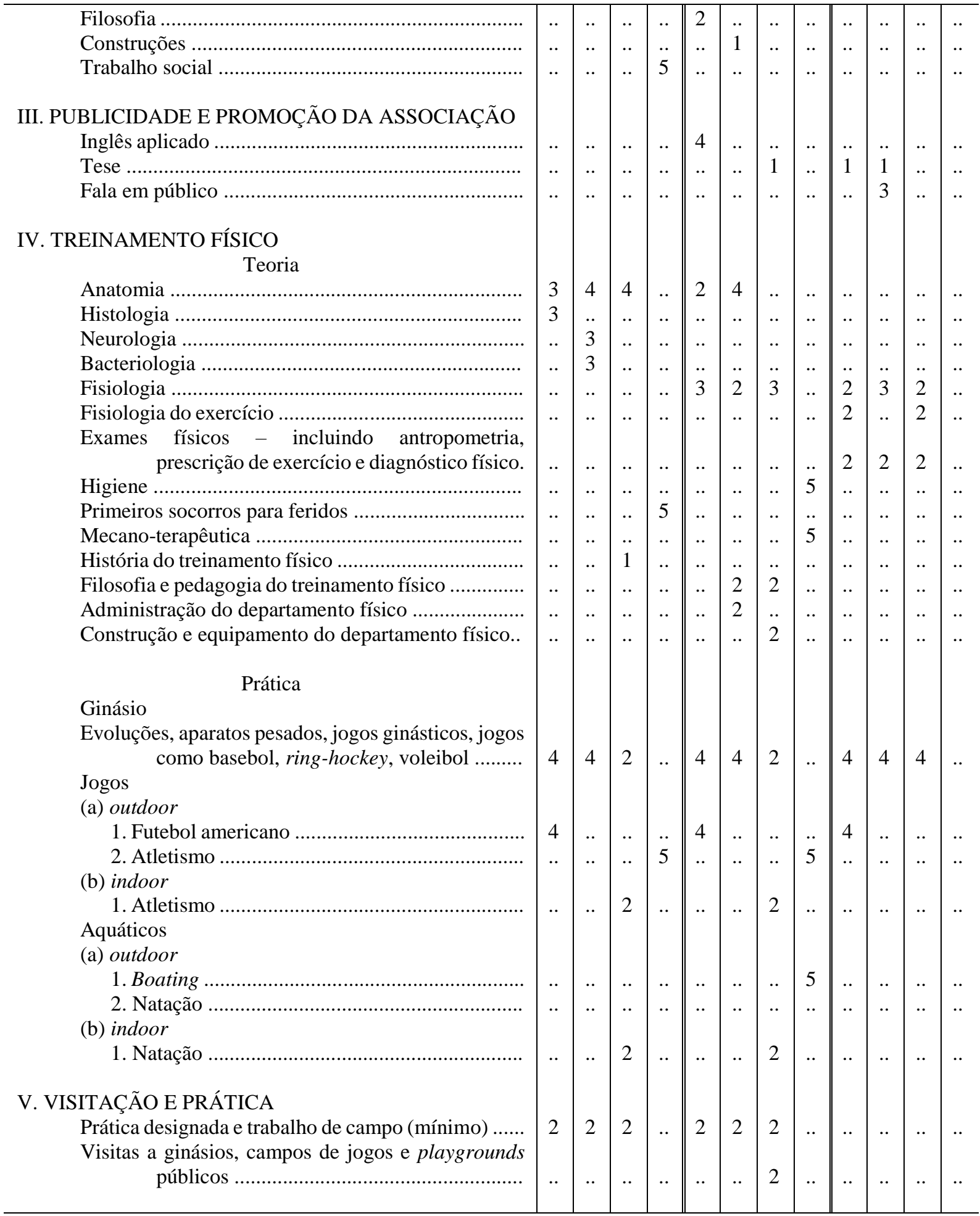

Fonte: The Institute and Training School of Young Men's Christian Associations. Catalog and annual announcement. May, 1908, p. 45. Box 114. George Williams College: an inventory of its records. Kautz Family YMCA Archives. University of Minnesota (tradução livre).

Os requisitos para a aprovação do aluno consistiam no cumprimento da carga horária do curso, na demonstração de qualidades necessárias para organizar com sucesso o trabalho na Associação e na elaboração de uma tese, que pudesse ser reconhecida pela originalidade da pesquisa.

Rev. Iberoam. Patrim. Histórico-Educativo, Campinas (SP), v. 4, n. 1, p. 38-51, jan./jun. 2018 


\section{A FORMAÇÃO DE GAELZER E ANDRADE}

Passados alguns anos, a instituição já denominada The Young Men's Christian Association College, apresenta com mais ênfase nos detalhes, os requisitos exigidos para os candidatos ao secretariado da Associação:

a. Boa saúde e uma personalidade atraente.

b. Capacidade de fazer e manter amigos, habilidade de cooperar com os outros e liberdade de excentricidades marcadas no hábito, maneira ou aparência.

c. Senso de boa conduta e bom senso, com potencial capacidade executiva, iniciativa e tato.

d. Uma educação liberal, de preferência um curso de faculdade ou seu equivalente, com a vontade de procurar qualquer formação e experiência profissional especial, pode ser necessária.

e. Adesão leal a uma igreja evangélica, forte caráter e convicções cristãs, liderança religiosa, um propósito de sacrifício e capacidade de ajudar religiosamente jovens e meninos.

f. Ausência da menor sugestão de delinquência moral. É absolutamente essencial que um líder da Associação, por causa de seu contato íntimo com homens e meninos, seja moralmente acima de qualquer reprovação ${ }^{12}$.

Como elementos da identidade institucional, as condições para candidatura ao curso explicitavam eixos orientadores do projeto acemista antes mesmo do início da formação. Saúde, capacidade executiva, repertório de saberes, religiosidade, altruísmo, moralidade. A Associação dizia que a demanda não era por mais homens, mas por aqueles que tivessem tais capacidades e aspectos de personalidade. Deixar mais evidente as características exigidas para admissão no curso era também dizer que assumir funções no interior da ACM não era para qualquer um, mas para uma elite que a Associação pretendia formar.

Na nova organização de preparação, os departamentos de instrução foram reduzidos a quatro, e revestidos de ciência logo na nomenclatura: ciência da Associação (responsável pelos estudos em administração geral, boy's work, county work, community work, industrial work, transportation work e inglês), religião e ética (encarregado pelos estudos da bíblia, da igreja cristã e de educação religiosa), ciência social (responsável pela instrução em psicologia, sociologia e economia) e ciência física (incumbido da educação física, da biologia compreendendo zoologia, anatomia, fisiologia e higiene - e das atividades físicas). No projeto de formação do secretariado das ACM's, o College redesenhava seus espaços, sua nomenclatura, anunciando por meio de uma alteração linguística, um novo elemento de

\footnotetext{
12 The Young Men's Christian Association College. Announcements for 1921-22. May, 1921, p. 29. Box 114. George Williams College: an inventory of its records. Kautz Family YMCA Archives. University of Minnesota (tradução livre).
} 
potencial reconhecimento: a ciência. Da organização anterior, vivenciada por Sims, não mais compunham-se como departamento a promoção e publicidade da Associação, e a visitação e prática de trabalho. Talvez como diferença mais significativa, o apartamento dos estudos bíblicos e sociais, os primeiros passaram a ser focados na instrução religiosa e os últimos configurados como conhecimento científico. Nos encontros e desencontros desses saberes, o College demarca limites para religião e ciência, ao mesmo tempo que anuncia sua complementariedade. Não era possível formar um secretariado que não partilhasse significados de ambas referências culturais.

A estrutura do curso também sofreu modificações. Quando Gaelzer e Andrade ali estudaram, todos os alunos do College division teriam as mesmas matérias durante os dois primeiros anos, e em seguida, aconteceriam as especializações para cada curso. A formação para diretores físicos totalizaria assim quatro anos de preparação. $\mathrm{O}$ ano acadêmico era composto por três períodos - outono, inverno e primavera - de 11 a 12 semanas cada.

Tabela 2: Currículo do College division para a formação em Educação Física em 1921.

\begin{tabular}{|c|c|}
\hline \multicolumn{2}{|l|}{$\begin{array}{c}\text { CURSO GERAL (PRIMEIRO E SEGUNDO ANOS) } \\
\text { PRIMEIRO ANO }\end{array}$} \\
\hline Matérias do Outono & Crédito \\
\hline 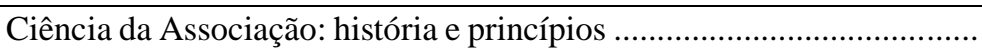 & $1 / 2$ \\
\hline 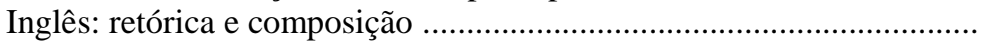 & 1 \\
\hline Zoologia: introdução ........................ & 1 \\
\hline Bíblia: ética cristã ............................ & $1 / 2$ \\
\hline Atividades físicas ............................................. & $1 / 2$ \\
\hline Matérias do Inverno & Crédito \\
\hline Ciência da Associação: história e princípios ..... & $1 / 2$ \\
\hline 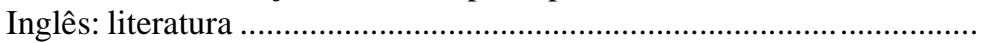 & 1 \\
\hline Fisiologia: introdução .................................... & 1 \\
\hline Atividades físicas & 1 \\
\hline Matérias da Primavera & Crédito \\
\hline Ciência da Associação: relações da Associação ........................................ & $1 / 2$ \\
\hline 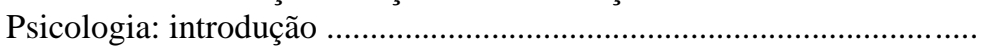 & 1 \\
\hline 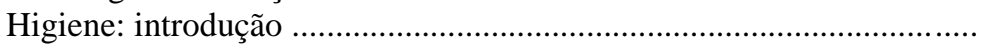 & $1 / 2$ \\
\hline Inglês: falar em público .......... & $1 / 2$ \\
\hline Atividades físicas ................... & $1 / 2$ \\
\hline
\end{tabular}

\section{SEGUNDO ANO}

\begin{tabular}{|c|c|}
\hline Matérias do Outono & Crédito \\
\hline 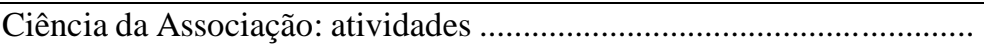 & 1 \\
\hline Bíblia: introdução bíblica ............ & 1 \\
\hline 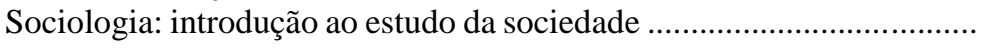 & 1 \\
\hline Atividades físicas ${ }^{*}$ & $1 / 2$ \\
\hline 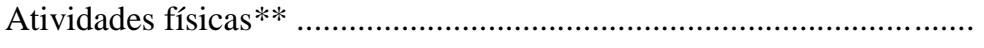 & $1 / 2$ \\
\hline Matérias do Inverno & Crédito \\
\hline
\end{tabular}


Ciência da Associação: contabilidade**

Bíblia: história do novo testamento e literatura

Economia: introdução

Anatomia: histologia*

Atividades físicas*

Atividades físicas**

\section{Matérias da Primavera}

Ciência da Associação: construções

Ciência da Associação: relações mundiais

Bíblia: história do novo testamento e literatura

Psicologia: psicologia social**

Ciência física: física e química aplicadas*

Atividades físicas*

Atividades físicas**

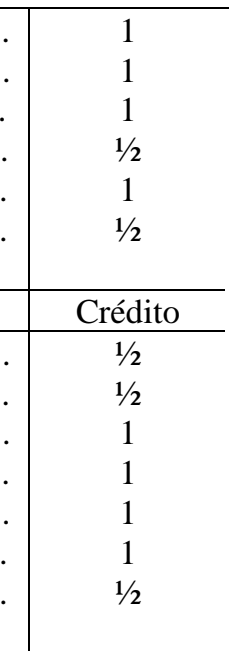

* Para estudantes do curso em Educação Física

** Para estudantes dos cursos em administração secretarial

\section{EDUCAÇÃO FÍSICA (TERCEIRO E QUARTO ANOS)}

TERCEIRO ANO

\begin{tabular}{|c|c|}
\hline Matérias do Outono & Crédito \\
\hline Educação Física: campo, história e princípios da Educação Física ......... & 1 \\
\hline 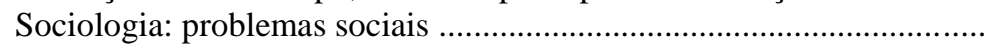 & 1 \\
\hline 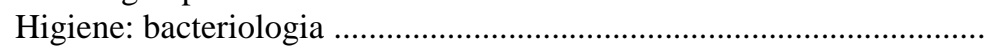 & 1 \\
\hline 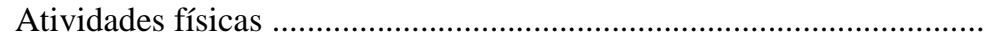 & $1 / 2$ \\
\hline Matérias do Inverno & Crédito \\
\hline Educação Física: Equipamentos do departamento físico ..... & $1 / 2$ \\
\hline 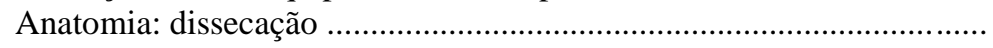 & 1 \\
\hline 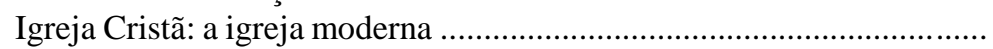 & 1 \\
\hline 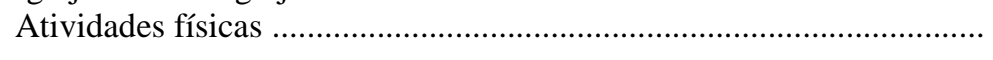 & 1 \\
\hline Matérias da Primavera & Crédito \\
\hline $\begin{array}{l}\text { Educação Física: organização e administração do departamento físico.. } \\
\text { Higiene: antropometria e diagnóstico físico } \\
\text { Higiene: primeiros socorros . }\end{array}$ & $\begin{array}{c}1 \\
1 \\
1 / 2 \\
1\end{array}$ \\
\hline \multicolumn{2}{|l|}{ QUARTO ANO } \\
\hline Matérias do Outono & Crédito \\
\hline Educação Física: seminário em Educação Física . & 1 \\
\hline 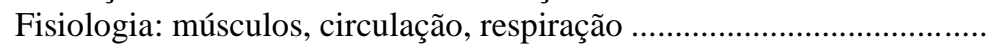 & 1 \\
\hline 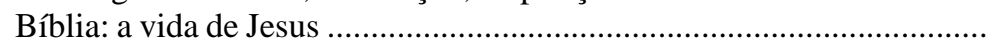 & 1 \\
\hline 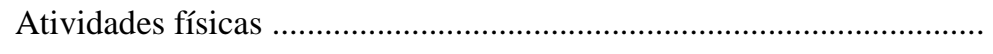 & $1 / 2$ \\
\hline Matérias do Inverno & Crédito \\
\hline Higiene: massagem ....... & $1 / 2$ \\
\hline 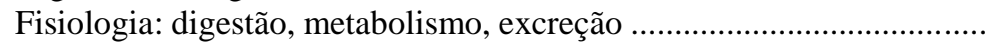 & 1 \\
\hline 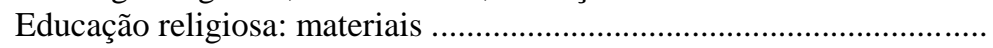 & 1 \\
\hline 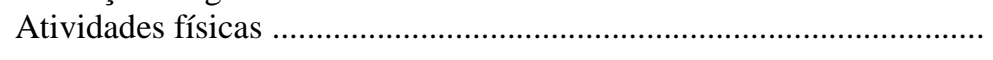 & 1 \\
\hline Matérias da Primavera & Crédito \\
\hline Bíblia: fundamentos cristãos & 1 \\
\hline 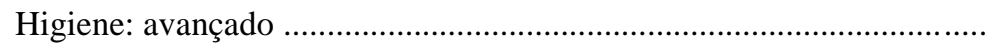 & 1 \\
\hline 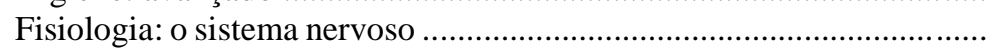 & $1 / 2$ \\
\hline Anatomia: neurologia ................. & $1 / 2$ \\
\hline
\end{tabular}




\begin{tabular}{l|c}
\hline Atividades físicas ........................................................................... & $1 / 2$ \\
\hline $\begin{array}{l}\text { Total de } 42 \text { créditos necessários para obter o grau acadêmico de bacharel em Ciências } \\
\text { da Associação, em Educação Física. }\end{array}$
\end{tabular}

Fonte: The Young Men's Christian Association College. Announcements for 1921-22. May, 1921. Box 114. George Williams College: an inventory of its records. Kautz Family YMCA Archives. University of Minnesota (tradução livre).

Todo esse processo formativo no College tinha um custo. As despesas educacionais incluíam a taxa de matrícula, o pagamento das matérias estudadas, um depósito caução (para ser usado caso o aluno fosse responsável por algum dano à instituição), um valor para o uso de vestiário e toalhas acrescido de uma taxa desse serviço, os custos de diferentes laboratórios (zoologia, anatomia, fisiologia, higiene, física e química aplicadas) e o pagamento referente à graduação. Denominadas como outras despesas do currículo, encontravam-se os livros de texto, cadernos e periódicos da Associação, os materiais ginásticos e a taxa atlética estudantil.

Para estudantes estrangeiros que vislumbravam retornar aos países de origem e trabalhar na Associação Cristã de Moços, bolsas de estudos eram uma possibilidade de terem diminuídas as despesas com a formação nos Estados Unidos. As bolsas eram mantidas por um fundo especial composto por associações interessadas, amigos, comitês nacionais e internacionais. Algumas orientações regulavam o processo de distribuição do auxílio: o pedido deveria ser feito antecipadamente em formulário especial, o candidato deveria ser aprovado pelo College e pelo comitê nacional do país de origem ou pelo departamento de trabalho estrangeiro do comitê internacional, e a bolsa poderia ser suspensa, mediante aviso prévio, caso houvesse alguma razão suficiente que levasse o College ou comitê nacional ou internacional a interromper o subsídio ao aluno ${ }^{13}$. No estabelecimento de assistência aos estudantes estrangeiros, a expectativa da Associação era que o aporte financeiro investido na formação retornasse em benefício próprio quando, formados como secretários gerais, diretores físicos ou outras especialidades, pudessem ocupar cargos nas ACM's.

Nos documentos do College, Gaelzer consta como aluno do primeiro ano de curso, subsidiado por bolsa de estudos, no período de 1919-1920. Para o ano letivo seguinte, 19201921, Gaelzer aparece no segundo ano de formação e Renato Andrade iniciava seus estudos, os dois contemplados com bolsa ${ }^{14}$.

\footnotetext{
13 The Young Men's Christian Association College. Announcements for 1921-22. May, 1921. Box 114. George Williams College: an inventory of its records. Kautz Family YMCA Archives. University of Minnesota.

14 The Young Men's Christian Association College. Announcements for 1920-21. April, 1920, p. 29. Box 114. George Williams College: an inventory of its records. Kautz Family YMCA Archives. University of Minnesota.
} 
Em 1923, a Mocidade anunciava que em junho daquele ano fora autorizada verba para o regresso de Gaelzer e Andrade que se encontravam em estudos nos Estados Unidos ${ }^{15}$. Se as fontes indicam a vinculação dos dois brasileiros à instituição formativa em Chicago, não é possível afirmar que eles concluíram os estudos no College. Para Andrade, uma evidência, porque a repetição incessante no primeiro ano nos permite supor que não cumpriu os requisitos para aprovação. No caso de Gaelzer, o aparecimento de seu nome só até o segundo ano de curso e a inscrição em seu currículo dos estudos na Universidade de Chicago, podem sugerir que ele tenha diplomado-se pelo curso combinado desta com o College. Em setembro daquele mesmo ano, o periódico acemista, referindo-se à ACM de Porto Alegre, registrava que era “ansiosamente esperado o sr. Gaelzer, director de educação physica, de regresso dos Estados Unidos" ". Já em outubro, noticiava a realização de uma festa, "que tambem teve o caracter de recepção em honra do senhor Renato de Andrade, que regressou dos Estados Unidos"17.

\section{CONSIDERAÇÕES FINAIS}

Constituir-se como diretor físico na YMCA pressupunha uma preparação técnica com ênfase nos conhecimentos biológicos - higiene, anatomia, fisiologia, etc. - mas também com acesso aos saberes dedicados à psicologia, sociologia e filosofia que permitiriam o trato do jovem a partir de uma perspectiva social. Pensada a partir da intencionalidade de ocupação de cargos acemistas, a formação demandou ainda a compreensão da estrutura e política interna da Associação. $\mathrm{O}$ acesso a diferentes práticas de exercícios físicos também configurou os estudos de Sims, Gaelzer e Andrade promovidos pela YMCA. Ao constituir uma identidade profissional para os que trabalhariam com a Educação Física, é possível operar com os sujeitos em formação e atuação na Associação Cristã de Moços a partir de uma chave interpretativa anunciada por Gomes e Hansen que permite pensar "os intelectuais mediadores que dirigiram suas ações para a formação de profissionais em sua própria área de especialidade, objetivando disseminar práticas e saberes que seriam responsáveis por circunscrever campos disciplinares e conferir uma identidade a seus membros” (2016, p. 20). Os diretores físicos ali formados parecem atuar dessa forma tanto no interior da Associação, quanto no espraiamento de ações relativas à formação do professorado do ensino primário, à construção de praças de jogos, à presença do esporte nos diferentes espaços urbanos. A modelagem aprendida/produzida/ensinada pelos

\footnotetext{
15 Mocidade, agosto de 1923, n. 354.

${ }^{16}$ Mocidade, setembro de 1923, n. 355, p. 16.

${ }^{17}$ Mocidade, outubro de 1923, n. 356, p. 9.
} 
diretores físicos acemistas esteve presente na constituição da Educação Física brasileira como disciplina escolar e também em outros espaços sociais (SILVA, 2017).

Por fim, destaque-se que os documentos institucionais recrutados no Kautz Family YMCA Archives, em Minneapolis, nos Estados Unidos, convidam a outras possibilidades de garimpagem de fontes. A partir de um conjunto de indagações a respeito de outros países, a investigação em tais arquivos pode oferecer vestígios importantes para a produção de novas versões sobre a Young Men's Christian Association, seu trabalho missionário, a ressonância de empreendimentos na América e revelar conexões dos processos de constituição da Educação Física em diferentes países do referido continente.

\section{REFERÊNCIAS}

ALVES, Cláudia. Jean-François Sirinelli e o político como terreno da história cultural. In: LOPES, Eliane Marta Teixeira; FARIA FILHO, Luciano Mendes de (Orgs.). Pensadores sociais e a história da educação II. Belo Horizonte: Autêntica Editora, 2012. p. 111-133.

FARIA FILHO, Luciano Mendes de; CHAMON, Carla Simone; INACIO, Marcilaine Soares. Apresentação. In: FARIA FILHO, Luciano Mendes de; INÁCIO, Marcilaine Soares. (Orgs.). Políticos, literatos, professores, intelectuais: o debate político sobre educação em Minas Gerais. Belo Horizonte: Mazza Edições, 2009. p. 7-20.

FONSECA, Thais Nívia de Lima. Serge Gruzinski e as dinâmicas culturais na América colonial. Cultura histórica \& Patrimônio, Alfenas, v. 2, n. 1, p. 60-71, 2013.

GOMES, Angela de Castro; HANSEN, Patricia Santos. Apresentação. In:

(Orgs.). Intelectuais mediadores: práticas culturais e ação política. Rio de Janeiro: Civilização Brasileira, 2016. p. 7-37.

LE GOFF, Jacques. Documento/monumento. In: Enciclopédia Einaldi. Memória- História. Porto: Imprensa Nacional-Casa da Moeda, 1997. (v. 1)

SILVA, Giovanna Camila da. A Associação Cristã de Moços e experiências de escolarização da Educação Física no Brasil: sujeitos, ideias e práticas acemistas em circulação. 2017. 236 f. Tese (Doutorado em Educação) - Faculdade de Educação da UFMG, Belo Horizonte.

SIRINELLI, Jean-François. Os intelectuais. In: REMOND, René (Org.). Por uma história política. Rio de Janeiro: Fundação Getúlio Vargas, 2003. p. 231-269. 